\title{
A FUZZY MPMC MODEL TO EVALUATE THE REUSABILITY OF FAST-INNOVATIVE PRODUCTS
}

\author{
Shahin Kouchekian-Sabour, Ryerson University, Toronto, Canada
}

dx.doi.org/10.18374/RBR-13-3.4

\begin{abstract}
To deal with the problem of reusability evaluation in reverse logistics, products are categorized into two types: well established products, and products with fast innovations. The companion paper (Kouchekian-Sabour and Jenab, 2010), discusses a model, which applies a reliability based method for evaluating the reusability of used products; that model is applicable to well established products only. Here, the focus is on the reusability evaluation for the second category. To deal with it, a fuzzy multiple participant-multiple criteria (MPMC) decision making model is presented, which is a modified combination of two previous researches: the disposal cause analysis (DCA) matrix (Umeda et al., 2005), and the fuzzy analytical hierarchy process (AHP) method (Van Laarhoven and Pedrycz, 1983). A numerical example of the application of the presented model is illustrated.
\end{abstract}

Keywords: Fuzzy AHP, Value Lifetime, Physical Lifetime, Reuse, Remanufacturing, Reverse Logistics. 